\title{
Correlation of sleep quality and cardiac autonomic modulation in hemodialysis patients
}

\author{
Erika Ribeiro Carneiro ${ }^{1,2 *}$ \\ Luana Anaisse Azoubel ${ }^{1,2}$ \\ Raimunda Carneiro Dias ${ }^{1,2}$ \\ Carlos José Dias ${ }^{2,5}$ \\ Emanuelle Sousa Sá ${ }^{1,2}$ \\ Dyego Araujo Brito ${ }^{1,2}$ \\ Natalino Salgado Filho ${ }^{1,2}$ \\ Elton Freitas Santos ${ }^{1,2}$ \\ José Hermógenes Rocco ${ }^{6}$ \\ Cristiano Teixeira Mostarda ${ }^{3}$ \\ Mario Bernardo Filho ${ }^{4}$
}

\begin{abstract}
Objectives: Sleep disorders in patients on hemodialysis are frequent, but few studies correlate these disorders with autonomic dysfunction in these patients. This study aimed to verify whether clinical and laboratory variables and heart rate variability are associated with worse sleep quality verified by the Pittsburg subjective scale in patients on hemodialysis. Material and Methods: A cross-sectional study was performed on forty-eight patients. Epidemiological, clinical, and laboratory data were collected. After were performed by recording the heart rate variability and applied Pittsburg questionnaires, Beck anxiety index (BAI), and Beck depression index (BDI). The global PSQI score $>5$ indicates that a person is a poor sleeper, the patients were divided according to the scores in the Pittsburg questionnaire into good and poor sleepers and the differences between all variables were analyzed. Results: Forty-eight patients were evaluated and the prevalence of $68.7 \%(n=33)$ of poor sleep quality was verified. From the depression and anxiety questionnaires, it was found that only $18.7 \%(n=9)$ had criteria for depression. In the analysis of the sympathetic dysfunction parameters, it was found that in the group with good sleep quality in the frequency domain $\left(\mathrm{HFm}^{2}\right)$ and the LFnu in the group with worse sleep quality. There was a positive correlation between sleep quality scores the anxiety and depression scores. It is also verified that the variables LFnu had a positive correlation with higher scores of quality of sleep and HFnu had a negative correlation with the highest scores of quality of sleep. Conclusion: In patients undergoing hemodialysis, the poorest quality of sleep is correlated with worse cardiac autonomic modulation as well as higher scores on the depression and anxiety scales.
\end{abstract}

Keywords: Sleep Quality; Hemodialysis; Autonomic Nervous System Diseases.

\author{
*Corresponding author: \\ Erika Ribeiro Carneiro \\ E-mail: erikacarneiro0204@gmail.com / \\ erika30082005@yahoo.com.br
}

Received: November 5, 2020;

Accepted: March 8, 2021 


\section{INTRODUCTION}

Currently more than 2.5 million people are on renal replacement therapy worldwide and it is estimated that by 2030 this number is expected to double ${ }^{1,2}$. Among the many problems in physiology faced by patients on hemodialysis, sleep disorders (SD) are common conditions and frequently underdiagnosed in clinical practice, therefore it is important to investigate through interviews and questionnaires such as the one in Pittsburgh and Epworth to direct better use of the gold standard polysomnography, which is still not very accessible in our country. They are usually more frequent in hemodialysis than in chronic kidney disease (CKD) nondialysis dependent, and it has been verified in studies that there may be a worsening after starting dialysis therapy ${ }^{3,4}$.

The prevalence mean of SD is $44 \%(20-83 \%)^{4,5}$ and may be subdivided into insomnia, sleep apnea, restless legs syndrome and excessive daytime sleepiness or be related to depression (another condition prevalent in these patients) ${ }^{6}$.

Some sleep disorders are linked to worsening hypertension and cardiovascular diseases such as obstructive sleep apnea and restless legs syndrome ${ }^{7}$, however, in other disorders this association is not clear. An important multicenter study with 11,351 patients from 7 countries found a $49 \%$ prevalence of sleep disorders in patients on hemodialysis, associated with lower quality of life scores, physical inactivity, use of some medications, cardiovascular disease, and increased serum phosphorus levels.

Concerning the autonomic nervous system in chronic renal patients, different studies demonstrate an imbalance between sympathetic and parasympathetic activity with alteration of tone and neural reflexes, leading to the deleterious effects of sympathetic hyperactivity, which may contribute to the increased incidence of sudden death in this population ${ }^{9-11}$.

The biological effects of CKD on sleep can be partially explained by the hyperreactivity of the sympathetic nervous system, decreased baroreflex activity leading to continuous stimulation of the renin-angiotensin-aldosterone system and nondipper pattern of blood pressure commonly seen in chronic renal patients, being associated worse cardiovascular outcomes ${ }^{12-16}$.

Sympathetic hyperreactivity may partially explain episodes of intradialytic hypertension and refractory hypertension. Decreased heart rate and baroreflex function variability has been associated with increased morbidity and mortality in hemodialysis patients ${ }^{17}$. It is postulated that one of the mechanisms of sleep disorders in chronic renal patients may also be due to increased activation of the sympathetic nervous system ${ }^{18}$.

Many studies have been done evaluating sleep disorders in hemodialysis patients, but few studies that correlate these disorders with autonomic dysfunction in these patients. The aim of this study was to verify whether clinical and laboratory variables and heart rate variability are associated with worse sleep quality verified by the Pittsburg subjective scale in patients on hemodialysis.

\section{MATERIAL AND METHODS}

\section{Sample}

A cross-sectional study was performed in 152 patients undergoing hemodialysis therapy in two centers of hemodialysis at Maranhão, from October 2018 to June 2019. From this total 66 were included in previous research, of which 48 completed all evaluations and questionnaires. The study was authorized by the ethics committee (CEP), CAAE: 99019318.0.0000.5086.

The survey included only adults' patients who had been enrolled in the service for at least 3 months. Patients with heart disease (arrhythmias, coronary disease, and heart failure) debilitating active or chronic lung disease and patients with neurological deficits were not included. Epidemiological, clinical and laboratory data were collected from individuals with chronic kidney disease on hemodialysis and electrocardiogram were performed to analyze heart rate variability.

After signing the consent form, patients answered a questionnaire with demographic information, clinical history (gender, age, residence, education, and income) and information about hemodialysis sessions (frequency and duration of sessions per week, time in hemodialysis, and shift). Physical examination was done verifying weight, height, body mass index (BMI), and blood pressure. Blood samples were collected for the following exams: hemoglobin, calcium, phosphate, urea, glycemia, HDL cholesterol, LDL cholesterol, parathormone, alkaline phosphatase, ferritin, potassium, albumin, and creatinine and analyzed in institution's laboratory. The Kt/V - number used in nephrology to calculate the dialysis dose - should be above 1.2, where: $\mathrm{K}$ (urea kinetics), $\mathrm{T}$ (time), and $\mathrm{V}$ (volume of urea distribution). In another day was performed by recording the heart rate variability (HRV) and applied Pittsburg questionnaires, Beck anxiety index (BAI) and Beck depression index (BDI).

\section{Heart rate variability (HRV)}

To extract signals to $H R V$ was realized an eletrocardiogram 12-leads utilizing the device micromed wincardio (Micromed WinCardio, v. 6.1.1 software) to obtain R-R intervals. The exam was realized in a silent room, the patient was instructed not to speak during exam and remain the supine position during 10 minutes while the exam was performed. After exam the intervals R-R series were extrated in format txt using software wincardio, HRV indices were analyzed using Kubios HRV software, version 3.2 (Biosignal Analysis and Medical Imaging Group, Kuopio, Finland).

The software converts signals $\mathrm{R}-\mathrm{R}$ to digital electrocardiogram in variables to examine autonomic nervous system function. All dates were disposable after correct about filter artefacts and were used SDNN (standard deviation of RR intervals) and RMSSD (Root mean square of successive RR intervals differences) in the time-domain. In frequency-domain were utilized low frequency (LFms ${ }^{2}$ ) (LFnu-normalized) and high frequency $\left(\mathrm{HFms}^{2}\right.$ ) (HFnu-normalized) bands in milliseconds and percentage, that represents predominantly sympathetic and parasympathetic modulation, respectively, and $\mathrm{LF} / \mathrm{HF}$ ratio as representative vagal sympathetic balance ${ }^{19,20}$.

\section{Pittsburg sleep quality index}

Sleep quality was analyzed based on the instrument called Pittsburgh sleep quality index (PSQI), elaborated by Buysse et 
al. $(1989)^{23}$, tested and validated in Brazil ${ }^{24}$. The questionnaire, applied in this study in the form of an interview, consists of 19 questions regarding quality and sleep disorders in the last month. The questionnaire evaluates seven components of sleep: subjective quality, sleep latency, sleep duration, sleep efficiency, sleep disorders, medication use, and daily dysfunction. For each component, the score can vary from 0 to 3 , with the upper limit representing greater component impairment. The total sum of the scores generates results ranging from 0 to 21 . The global PSQI score $>5$ indicates that a person is a 'poor sleeper' having severe difficulties in at least two areas or moderate difficulties in more than three areas.

\section{Beck anxiety index}

The BAI is a self-reported scale that measures the intensity of anxiety symptoms. The scale was built based on several auto-reporting instruments used in the CСТ (Center for Cognitive Therapy), from which items were selected to compose the Inventory. The inventory consists of 21 items with descriptive statements of anxiety symptoms and should be evaluated by the subject with reference to himself, on a scale of four points, which, according to the manual reflect levels of increasing severity of each symptom: 1) absolutely not; 2) slightly: did not bother me much; 3) moderately: was very unpleasant, but I could bear it; 4) severely: could hardly bear it ${ }^{25}$.

\section{Beck depression index}

The BDI is composed of 21 items that include the cognitive, affective, behavioral, and somatic components of depression. Each item contains four statements that vary in intensity ( 0 to 3 ), with the individual indicating which of the four statements best describes his symptoms. The final score is obtained by adding together the 21 items that make up the scale, resulting in the following normatization, according to the Cognitive Therapy Center: (a) no depression or minimum depression: final scores less than 11 points; (b) mild to moderate depression: final scores between 12 and 19 points; (c) moderate to severe depression: final scores between 20 and 35 points; and (d) severe depression: final scores between 36 and 63 points ${ }^{25}$.

\section{Statistical analysis}

All data were presented in mean and standard deviation. The Shapiro-Wilk test was applied to verify the normality of the data. The parameters of interest were analyzed using unpaired Student's t-test or Mann-Whitney U test depending on normality. The chi-square test or Fisher's test was applied to verify if there is an association between the qualitative variables. Pearson's and Spearman's correlations were verified on the variables. The results were considered statistically significant for the value $p<0.05$. For data analysis, GraphPad Prism version 8.0.0 for Mac OSx, GraphPad Software, San Diego, California, U.S.A., www.graphpad.com was used.

\section{RESULTS}

Forty-eight patients were evaluated and the prevalence of $68.7 \%(n=33)$ of poor sleep quality was verified. From the depression and anxiety questionnaires, it was found that only $18.7 \%(\mathrm{n}=9)$ had criteria for depression (mild to severe) and $22.9 \%(\mathrm{n}=11)$ mild to severe anxiety. The most frequent etiology found was chronic glomerulonephritis $29.1 \%(\mathrm{n}=14)$ followed by undetermined cause $25 \%(\mathrm{n}=12)$ reflecting the relatively young population (mean age $48.32 \pm 12.37$ years) of this study. Hypertensive nephrosclerosis and nephropathy diabetic were found in $20.8 \%(n=10)$ and $10.4 \%(n=5)$ of patients, respectively. The mean time in hemodialysis was $61.44^{ \pm} 45.8$ months. The mean BMI was $23.8 \pm 4$.0. There were no significant differences regarding the use of antihypertensives, with 4 patients $(26.6 \%)$ in the good sleepers group and 11 patients $(33.3 \%)$ in the poor sleepers group using ARB or ACE inhibitors $(p=0.23)$ and 5 patients $(33.3 \%)$ in the good sleepers group and 10 patients $(30.3 \%)$ in the poor sleepers group using betta-blockers $(p=0.99)$.

The socio-demographic variables analyzed were $70 \%(n=33)$ of the patients had more than 8 years of formal education, $79 \%(n=38)$ of the patients were from the city where they were on dialysis, and $75 \%(\mathrm{n}=36)$ of the patients were on the night shift, and average monthly income of 397 dollars, when we divided the patients as to the quality of sleep these variables did not show interference (Table 1).

Table 1. Clinical and demographic characteristics of good sleepers compared with poor sleepers in hemodialysis.

\begin{tabular}{l|c|c|c}
\hline Variable & $\begin{array}{c}\text { Good sleepers } \\
\text { PSQI < 5 (15) }\end{array}$ & $\begin{array}{c}\text { Poor sleepers } \\
\text { PSQI >5 (33) }\end{array}$ & p-value \\
\hline BAI & $5.66 \pm 6.68$ & $9.8 \pm 9.09$ & 0.12 \\
\hline BDI & $5.00 \pm 3.63$ & $11.65 \pm 8.68$ & $0.004^{*}$ \\
\hline Sleep quality & $3.60 \pm 1.35$ & $8.43 \pm 2.67$ & - \\
\hline Vintage HD & $45.4 \pm 28.6$ & $65.7 \pm 51.6$ & 0.32 \\
\hline Age (years) & $46.4 \pm 14.3$ & $49.2 \pm 11.9$ & 0.48 \\
\hline Presence of diabetes & $2 / 1513.3 \%$ & $5 / 3315.1 \%$ & $n s$ \\
\hline Women/men & $8 / 7$ & $14 / 18$ & 0.75 \\
\hline BMI & $23.7 \pm 3.83$ & $24.3 \pm 4.15$ & 0.65 \\
\hline SBP (mmHg) & $132.3 \pm 18.8$ & $138.3 \pm 19.5$ & 0.32 \\
\hline DBP (mmHg) & $84 \pm 10.6$ & $86.3 \pm 10.8$ & 0.50 \\
\hline 6-min WT (meters) & $412.1 \pm 108.9$ & $444.3 \pm 96.4$ & 0.28 \\
\hline Scholarity & & & \\
\hline$<8$ years & $2 / 1513.3 \%$ & $12 / 3336.3 \%$ & 0.17 \\
\hline$>8$ years & $13 / 1586.6 \%$ & $21 / 3363.6 \%$ & \\
\hline Distance of centre dialysis & $13 / 1586.6 \%$ & $25 / 3375.7 \%$ & 0.47 \\
\hline Near (same city) & $2 / 1513.3 \%$ & $8 / 3324.2 \%$ & 0.07 \\
\hline Far (different city) & $1 / 156.6 \%$ & $11 / 3333.3 \%$ & \\
\hline Shift Evening & $14 / 1593.3 \%$ & $22 / 3366.6 \%$ & \\
\hline night & & & \\
\hline
\end{tabular}

Notes: PSQI = Pittsburgh sleep quality index; BAI = Beck anxiety index; BDI = Beck depression index; $\mathrm{BMI}=$ Body mass index; $\mathrm{SBP}=$ Systolic blood pressure; $\mathrm{DBP}=$ Diastolic blood pressure; 6-min W'T (6 minutes walking test); *Mann Whitney; \#Fisher test.

Clinical variables such as time on hemodialysis, age, gender, BMI, blood pressure, presence of diabetes mellitus, and the cardiopulmonary capacity inferred by the walking test did not differ between groups with good and bad sleep quality (Table 1). Among the laboratory tests, no difference was observed either (Table 2). In the analysis of the sympathetic dysfunction parameters, it was found that in the group with good sleep quality in the frequency 
Table 2. Laboratory data of good sleepers compared with poor sleepers in hemodialysis.

\begin{tabular}{|l|c|c|c|}
\hline Variable & $\begin{array}{c}\text { Good sleepers } \\
\text { PSQI < 5 (15) }\end{array}$ & $\begin{array}{c}\text { Poor sleepers } \\
\text { PSQI >5 (33) }\end{array}$ & p-value \\
\hline Phosphate (mg/dL) & $4.59 \pm 1.05$ & $4.58 \pm 1.01$ & 0.97 \\
Calcium (mg/dL) & $9.02 \pm 0.74$ & $8.90 \pm 0.79$ & 0.63 \\
Calcium x phosphate product & $41.8 \pm 11.9$ & $40.78 \pm 9.59$ & 0.74 \\
\hline Urea (mg/dL) & $121.5 \pm 37.6$ & $131.1 \pm 34.4$ & 0.39 \\
\hline Potassium mmol/L & $4.89 \pm 0.79$ & $5.16 \pm 0.93$ & 0.33 \\
Hemoglobin (g/dL) & $11.5 \pm 1.60$ & $11.15 \pm 1.82$ & 0.32 \\
Glycemia (mg/dL) & $91.7 \pm 20.9$ & $107.7 \pm 37.9$ & 0.31 \\
HDL cholesterol (mg/dL) & $39.2 \pm 13.9$ & $40.3 \pm 15.2$ & 0.81 \\
LDL cholesterol (mg/dL) & $91.7 \pm 19.5$ & $99.5 \pm 29.1$ & 0.44 \\
PTH pg/ml & $675.6 \pm 443.9$ & $472.9 \pm 413.5$ & 0.08 \\
Alkaline phosphatase U/1 & $161.5 \pm 55.8$ & $152.9 \pm 137$ & 0.07 \\
Ferritin (ng/mL) & $395.9 \pm 179.7$ & $618.9 \pm 468.8$ & 0.18 \\
albumin (g/dL) & $4.26 \pm 0.41$ & $4.18 \pm 0.57$ & 0.38 \\
KTVe & $1.40 \pm 0.26$ & $1.27 \pm 0.38$ & 0.23 \\
\hline
\end{tabular}

Notes: PTH = Parathyroid hormone; PSQI = Pittsburgh sleep quality index; KTVe $\mathrm{K}$ (urea kinetics), $\mathrm{T}$ (time), and $\mathrm{V}$ (volume of urea distribution).

domain (HFm2) it shows higher integrity of the parasympathetic nervous system and in the LFnu it shows higher sympathetic modulation in the group with worse sleep quality (Table 3). In time domain the RMSSD index was numerically lower in the group with higher PSQI, but not statistically significant.

There was a positive correlation of the sleep quality scores with the anxiety and depression scores (Table 4, Figures 1A and 1B), demonstrating that these are conditions that are usually part of the picture associated with chronic diseases and that alter the quality of life. It is also verified that the variables of variability of heart rate in frequency domain LFnu (which indicates higher sympathetic modulation) had positive correlation with higher scores of quality of sleep and HFnu (which indicates parasympathetic integrity) had negative correlation as the highest scores of quality of sleep (Table 4, Figures $1 \mathrm{C}$ and 1D).

\section{DISCUSSION}

Hemodialysis patients have significant impairments in quality of life due to uremic symptoms, time spent on dialysis treatment (usually three times a week and four hours a day),

Table 3. Variables of heart rate variability (HRV) of good sleepers compared with poor sleepers in hemodialysis.

\begin{tabular}{lccc}
\hline Variable & $\begin{array}{c}\text { Good sleepers } \\
\text { PSQI < 5 (15) }\end{array}$ & $\begin{array}{c}\text { Poor sleepers } \\
\text { PSQI > 5 (33) }\end{array}$ & p-value \\
\hline mean RR (ms) & $798.9 \pm 91.4$ & $781.5 \pm 114.2$ & 0.60 \\
SDNN (ms) & $19.8 \pm 7.56$ & $16.13 \pm 6.22$ & 0.15 \\
RMSSD (ms) & $15.3 \pm 6.26$ & $11.63 \pm 6.63$ & 0.07 \\
LF ${\left(\mathbf{m s}^{2}\right)}^{\mathbf{H}}$ & $66.5 \pm 53.2$ & $62.3 \pm 64.5$ & 0.48 \\
HF (ms $)$ & $109.6 \pm 101.5$ & $58 \pm 63.7$ & $0.02^{*}$ \\
LF/HF & $1.21 \pm 1.05$ & $2.55 \pm 2.64$ & 0.05 \\
LFnu & $45.9 \pm 19.8$ & $59.3 \pm 21.1$ & $0.04^{\#}$ \\
HFnu & $53.9 \pm 19.7$ & $43.1 \pm 22.1$ & 0.11 \\
\hline
\end{tabular}

Notes: PSQI $=$ Pittsburgh sleep quality index; Mean RR = Mean intervals R-R; SDNN $=$ Standard deviation of RR intervals; RMSSD $=$ Root mean square of successive RR intervals differences; LF ms $2=$ Low frequency expressed ms2; LFnu $=$ Low frequency normalized HFms2 - high frequency expressed ms2; HFnu = High frequency normalized; $\mathrm{LF} / \mathrm{HF}=$ ratio-vagal sympathetic balance; ${ }^{*}$ Mann Whitney test; \#Unpaired t-test.

Table 4. Correlation of the Pittsburgh sleep scale with heart rate variability (HRV) parameters and Beck's depression and anxiety scales.

\begin{tabular}{lcc} 
Correlation Pittsburg & $\mathrm{r}$ & $p$ \\
\hline LF nu & 0.39 & $0.006^{*}$ \\
HF nu & -0.38 & $0.008^{*}$ \\
BDI & 0.47 & $0.006 \#$ \\
BAI & 0.36 & $0.014 \#$ \\
\hline
\end{tabular}

A

C

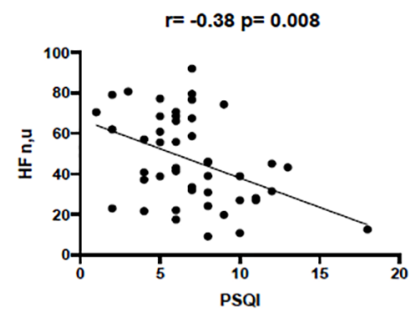

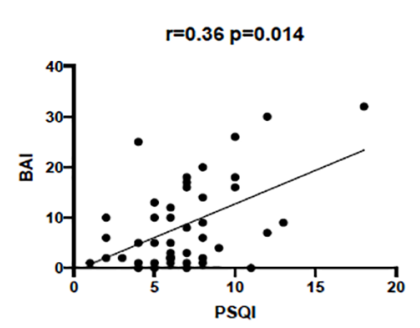

B

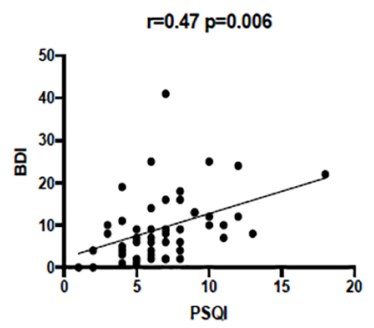

D

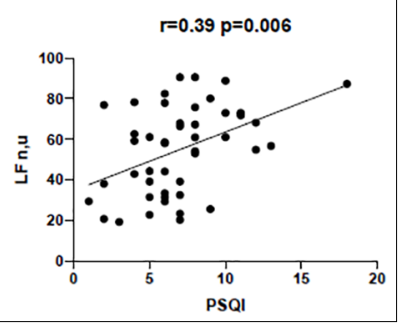

Figure 1. Correlations correlation of the Pittsburgh sleep scale with heart rate variability (HRV) parameters and Beck's depression and anxiety scales. A) BAI Beck and PSQI B) BDI Beck and PSQI C) HFnu and PSQI D) LFnu and PSQI.

financial difficulties generated by unemployment and early retirement, in addition to the impact due to bone and muscle pain caused by osteoarthritis and physical deformities due to the use of fistulas and catheters. All of these factors favor conditions of anxiety and depression that can impact the sleep quality.

These disorders (anxiety, depression, and sleep disorders), despite extensive literature on the subject, are often underdiagnosed in clinical practice ${ }^{26}$, and sometimes directed anamnesis and questionnaires are necessary, thus studies that correlate the importance of the subject in the impaired quality of life and cardiovascular risk of these patients. The present study did not verify that socio-demographic variables influenced on the worse quality of sleep. A Turkish study found an association with the patient's current unemployment ${ }^{27}$, but other studies including a Brazilian study did not find this association $^{28,29}$. Studies show that the poorest quality of sleep in hemodialysis patients was associated with low income $e^{30-33}$. However, this association was not verified in this study, in the state of Maranhão, most patients undergoing hemodialysis have low income and some unemployment insurance or sickness insurance, perhaps explaining the uniformity of the findings $\mathrm{s}^{34}$.

In previous studies, it appears that sleep quality was related to anemia ${ }^{35,36}$, hyperphosphatemia ${ }^{37,38}$, nutritional status ${ }^{39}$, uremic pruritus, hyperparathyroidism ${ }^{40}$, time on hemodialysis ${ }^{35}$, 


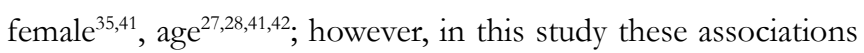
were not verified. A study by Bilgic et al. (2007) ${ }^{39}$ found that those patients with higher malnutrition and inflammation scores had worse sleep quality, in the present study the BMI, albumin, and serum ferritin did not differ between groups.

Although the sample of patients is small, it is observed that in the present study, laboratory and clinical variables were not associated with worse sleep quality, which may be due to the uniformity and availability of treatment of these patients for anemia, bone mineral disease, adequacy of dialysis with better technology in hemodialysis machines, and drug treatment (such as erythropoietin, phosphorus binders, and calcimmetics) involved.

It is observed in more recent studies that among the clinical and laboratory variables, only female gender ${ }^{41}$ and age $e^{41,42}$ were related to worse sleep quality. A recent study by Turkish researchers ${ }^{43}$ found an important correlation between sleep quality and the dialysis quality index (good dialysis index).

The association between poor sleep quality and sleep disorders and autonomic dysfunction is already well established in the literature ${ }^{44-47}$; however, in the hemodialysis population this association is still poorly studied. The normal phases of sleep are closely related to the autonomic nervous system, whereas in the non-REM phase the predominance of parasympathetic establishes a fall in heart rate and blood pressure, favoring cardiovascular protection, although in chronic kidney patients (especially those in chronic kidney phases advanced diseases) ${ }^{10-12}$, there is reduced parasympathetic modulation and sympathetic exacerbation, with repercussions on the cardiovascular system (absence of physiological nocturnal fall in blood pressure, left ventricular hypertrophy, and accelerated atherosclerosis) ${ }^{48}$, therefore, it is not surprising to find that in addition to previous autonomic dysfunction, these patients may have their condition aggravated by sleep disorders, anxiety and depression.

This study demonstrated that patients with worse sleep quality had parameters of heart rate variability with greater sympathetic hyperactivity, this being one of the few studies that correlates parameters of autonomic dysfunction in these patients with worse sleep quality ${ }^{49-51}$. A study by Chan et al. $(2004)^{49}$ found an improvement in autonomic dysfunction and apnea/hypopnea parameters in polysomnography of patients after switching from conventional to nighttime hemodialysis. Study with 14 Japanese patients found autonomic dysfunction (pNN50 and minor RMSSD) in patients on hemodialysis (regardless of whether hemodialysis was performed on the day of the exam) compared to controls ${ }^{50}$, demonstrating that parasympathetic activity in hemodialysis patients was lower during sleep than in the control group.

In study 2010, using polysomnography and recording of heart rate variability during sleep and wakefulness found that in patients with advanced stage CKD (CKD 4-5) and on hemodialysis, the parasympathetic tone does not increase as it should in the wake transition period for sleep, being one of the first studies to identify autonomic dysfunction during sleep in chronic kidney patients; however, it did not assess whether it would have an impact on sleep quality $y^{52}$. Therefore, further studies are needed to verify whether autonomic dysfunction is a cause or consequence of the worse quality of sleep seen in these patients.

This study has some limitations because it is a crosssectional study with a reduced number of patients due to the difficulty in applying the sleep questionnaire and performing the pre-dialysis before hemodialysis session heart rate variability electro. We did not have ambulatory blood pressure monitoring for all patients, mainly due to the protocol difficulty of taking the exam in 44 hours (on the day of dialysis and on the day without hemodialysis). The gold standard for checking polysomnography sleep disorder was not possible for equipment unavailability.

\section{CONCLUSION}

Thus, it can be concluded with this study that the quality of sleep correlates with Beck's scale of depression and anxiety in hemodialysis patients, therefore being important scales for screening these disorders that impact the quality of life of these patients, thus enables health professionals to act earlier. The worse quality of sleep verified by the Pittsburg sleep scale was also correlated with autonomic dysfunction in these patients, being an important marker of cardiovascular risk.

\section{ACKNOWLEDGMENTS}

Thanks the Conselho nacional de desenvolvimento científico tecnológico - $\mathrm{CNPq}$ for funding (Universal 442374/2014-3) and Fundação de Amparo à Pesquisa do Estado do Maranhão - FAPEMA (Universal 00358/15)

\section{REFERENCES}

1. Chan CT, Blankestijn PJ, Dember LM, Gallieni M, Harris DCH, Lok $\mathrm{CE}$, et al. Dialysis initiation, modality choice, access, and prescription: conclusions from a Kidney Disease: Improving Global Outcomes (KDIGO) Controversies Conference. Kidney Int. 2019 Jul;96(1):37-47. DOI: https://doi.org/10.1016/j.kint.2019.01.017

2. GBD Chronic Kidney Disease Collaboration. Global, regional, and national burden of chronic kidney disease, 1990-2017: a systematic analysis for the Global Burden of Disease Study 2017. Lancet. 2020 Feb;395(10225):709-33. DOI: https://doi.org/10.1016/S01406736(20)30045-3

4. Wu AW, Fink NE, Marsh-Manzi JV, Meyer KB, Finkelstein FO, Chapman MM, et al. Changes in quality of life during hemodialysis and peritoneal dialysis treatment: generic and disease specific measures. J Am Soc Nephrol. 2004 Mar;15(3):743-53. DOI: https://doi. org/10.1097/01.asn.0000113315.81448.ca

5. Rhee EP, Guallar E, Hwang S, Kim N, Tonelli M, Moe SM, et al. Prevalence and persistence of uremic symptoms in incident dialysis patients. Kidney360. 2020;1(2):86-92. DOI: https://doi.org/10.34067/ kid.0000072019

6. Murtagh FE, Addington-Hall J, Higginson IJ. The prevalence of symptoms in end-stage renal disease: a systematic review. Adv Chronic Kidney Dis. 2007 Jan;14(1):82-99. DOI: https://doi.org/10.1053/j. ackd.2006.10.001

7. Davison SN, Levin A, Moss AH, Jha V, Brown EA, Brennan F, et al. Executive summary of the KDIGO Controversies Conference on Supportive Care in Chronic Kidney Disease: developing a roadmap to improving quality care. Kidney Int. 2015 Sep;88(3):447-59.

8. NovakM,WinkelmanJW,UnruhM.Restlesslegssyndromeinpatientswith chronic kidney disease. Semin Nephrol. 2015 Jul;35(4):34758. DOI: https://doi.org/10.1016/j.semnephrol.2015.06.006

9. Elder SJ, Pisoni RL, Akizawa T, Fissell R, Andreucci VE, Fukuhara S, et al. Sleep quality predicts quality of life and mortality risk in haemodialysis patients: results from the Dialysis Outcomes and Practice Patterns Study (DOPPS). Nephrol Dial Transplant. 2008 Mar;23(3):998-1004. DOI: https://doi.org/10.1093/ndt/gfm630 
10. Zoccali C, Mallamaci F, Tripepi G, Parlongo S, Cutrupi S, Benedetoo FA, et al. Norepinephrine and concentric hypertrophy in patients with end-stage renal disease. Hypertension. 2002;40(1):41-6. DOI: https:// doi.org/10.1161/01.hyp.0000022063.50739.60

11. Masuo K, Lambert GW, Esler MD, Rakugi H, Ogihara T, Schlaich MP. The role of sympathetic nervous activity in renal injury and end-stage renal disease. Hypertens Res. 2010 Mar;33(6):521-8. DOI: https://doi. org $/ 10.1038 / \mathrm{hr} .2010 .35$

12. Schohn D, Weidmann P, Jahn H, Beretta-Piccoli C. Norepinephrinerelated mechanism in hypertension accompanying renal failure. Kidney Int. 1985 Nov;28(5):814-22.

13. Maung SC, El Sara A, Chapman C, Cohen D, Cukor D. Sleep disorders and chronic kidney disease. World J Nephrol. 2016 May;5(3):224-32. DOI: https://doi.org/10.5527/wjn.v5.i3.224

14. Amar J, Vernier I, Rossignol E, Bongard V, Arnaud C, Conte JJ, et al. Nocturnal blood pressure and 24-hour pulse pressure are potent indicators of mortality in hemodialysis patients. Kidney Int. 2000 Jun;57(6):2485-91.

15. Liu M, Takahashi H, Morita Y, Maruyama S, Mizuno M, Yuzawa Y, et al. Non-dipping is a potent predictor of cardiovascular mortality and is associated with autonomic dysfunction in haemodialysis patients. Nephrol Dial Transplant. 2003 Mar;18(3):563-9. DOI: https://doi. org $/ 10.1093 / \mathrm{ndt} / 18.3 .563$

16. Tripepi G, Fagugli RM, Dattolo P, Parlongo G, Mallamaci F, Buoncristiani U, et al. Prognostic value of 24-hour ambulatory blood pressure monitoring and of night/day ratio in nondiabetic, cardiovascular events-free hemodialysis patients. Kidney Int. 2005 Sep;68(3):1294-302.

17. Ataş N, Erten Y, Okyay GU, Inal S, Topal S, Önec K, et al. Left ventricular hypertrophy and blood pressure control in automated and continuous ambulatory peritoneal dialysis patients. Ther Apher Dial. 2014 Jun;18(3):297304. DOI: https://doi.org/10.1111/1744-9987.12104

18. Rubinger D, Backenroth R, Sapoznikov D. Sympathetic nervous system function and dysfunction in chronic hemodialysis patients. Semin Dial. 2013 Apr;26(3):333-43. DOI: https://doi.org/10.1111/sdi.12093

19. Turek NF, Ricardo AC, Lash JP. Sleep disturbances as nontraditional risk factors for development and progression of CKD: review of the evidence. Am J Kidney Dis. 2012 Nov;60(5):823-33. DOI: https://doi. org/10.1053/j.ajkd.2012.04.027

20. Johansson M, Gao SA, Friberg P, Annerstedt G, Calström J, Ivarsson $\mathrm{T}$, et al. Reduced baroreflex effectiveness index in hypertensive patients with chronic renal failure. Am J Hypertens. 2005 Jul;18(7):995-1016. DOI: https://doi.org/10.1016/j.amjhyper.2005.02.002

21. American Heart Association (AHA). Heart rate variability: tandards of measurement, physiological interpretation, and clinical use. Eur Heart J. 1996;17:354-81.

22. Enright PL. The six-minute walk test. Respir Care. 2003 Aug;48(8):783-5.

23. Soaresa MR, Pereira CA. Six-minute walk test: reference values for healthy adults in Brazil. J Bras Pneumol. 2011 Sep/Oct;37(5):576-83. DOI: https://doi.org/10.1590/s1806-37132011000500003

24. Buysse DJ, Reynolds CF, Monk TH, Berman SR, Kupfer DJ. The Pittsburgh sleep quality index: a new instrument for psychiatric practice and research. Psychiatry Res. 1989 May;28(2):193-213. DOI: https:// doi.org/10.1016/0165-1781(89)90047-4

25. Bertolazi AN, Fagondes SC, Hoff LS, Dartora EG, Miozzo ICS, Barba MEF, et al. Validation of the Brazilian Portuguese version of the Pittsburgh sleep quality index. Sleep Med. 2011 Jan;12(1):70-5. DOI: https://doi.org/10.1016/j.sleep.2010.04.020

26. Beck AT, Steer RA, Carbin MG. Psychometric properties of the Beck Depression Inventory: twenty-five years of evaluation. Clin Psychol Rev. 1998;8(1):77-100.

27. Jurado-Gamez B, Martin-Malo A, Alvarez-Lara MA, Muñoz L, Cosano A, Aljama P. Sleep disorders are underdiagnosed in patients on maintenance hemodialysis. Nephron Clin Pract. 2007;105(1):c35-c42. DOI: https://doi.org/10.1159/000096982

28. Guney I, Atalay H, Solak Y, Altintepe L, Toy H, Tonbul HZ, et al. Predictors of sleep quality in hemodialysis patients. Int J Artif Organs. 2010 Mar;33(3):154-60. DOI: https://doi.org/10.1177/039139881003300304

29. Araujo SM, Bruin VM, Daher EF, Medeiros CA, Almeida GH, Bruin PF. Quality of sleep and day-time sleepiness in chronic hemodialysis: a study of 400 patients. Scand J Urol Nephrol. 2011 Jun;45(5):359-64. DOI: https://doi.org/10.3109/00365599.2011.584694

30. Trbojević-Stanković J, Stojimirović B, Bukumirić Z, Hadzibulić E, Andrić B, Djordjević V, et al. Depression and quality of sleep in maintenance hemodialysis patients. Srp Arh Celok Lek. 2014 Jul/Aug;142(7-8):437-43.

31. Zubair UB, Butt B. Assessment of quality of sleep and its relationship with psychiatric morbidity and socio-demographic factors in the patients of chronic renal disease undergoing hemodialysis. J Coll Physicians Surg Pak. 2017 Jul;27(7):427-31.
32. Parvan K, Lakdizaij S, Roshangar F, Mostofi M. Quality of sleep and its relationship to quality of life in hemodialysis patients. J Caring Sci. 2013;2(4):295-304. DOI: https://doi.org/10.5681/jcs.2013.035

33. Lin KY, Lin YC, Wang HH. Differential effects of age on quality of sleep and depression in patients receiving maintenance haemodialysis. Psychogeriatrics. 2019 Feb;19(5):465-74. DOI: https://doi.org/10.1111/psyg.12424

34. Sariarslan HA, Gulhan YB, Unalan D, Basturk M, Delibas S. The relationship of sleep problems to life quality and depression. Neurosciences (Riyadh). 2015 Jul;20(3):236-42. DOI: https://doi.org/10.17712/nsj.2015.3.20150157

35. Coutinho NPS, Tavares MCH. Care of chronic renal patients undergoing hemodialysis, from the perspective of the user. Cad Saúde Coletiva. 2011;19(2):232-9.

36. Pai MF, Hsu SP, Yang SY, Ho TI, Lai CF, Peng YS. Sleep disturbance in chronic hemodialysis patients: the impact of depression and anemia. Ren Fail. 2007;29(6):673- 7. DOI: https://doi.org/10.1080/08860220701459642

37. Cengić B, Resić H, Spasovski G, Avdić E, Alajbegović A. Quality of sleep in patients undergoing hemodialysis. Int Urol Nephrol. 2012 Dec;44(2):557-67. DOI: https://doi.org/10.1007/s11255-010-9881-x

38. Ng ESY, Wong PY, Kamaruddin ATH, Lim CTS, Chan YM. Poor sleep quality, depression and social support are determinants of serum phosphate level among hemodialysis patients in Malaysia. Int J Environ Res Public Health. 2020;17(14):5144. DOI: https://doi.org/10.3390/ijerph17145144

39. Unruh M, Kurella Tamura M, Larive B, Rastogi A, James S, Schiller B, et al. Impact of sleep quality on cardiovascular outcomes in hemodialysis patients: results from the frequent hemodialysis network study. Am J Nephrol. 2011;33(5):398-406. DOI: https://doi.org/10.1159/000326343

40. Bilgic A, Akgul A, Sezer S, Arat Z, Ozdemir FN, Haberal M. Nutritional status and depression, sleep disorder, and quality of life in hemodialysis patients. J Ren Nutr. 2007 Nov;17(6):381-8. DOI: https://doi. org/10.1053/j.jirn.2007.08.008

41. Esposito MG, Cesare CM, Santo RM, Cice G, Perna AF, Violetti E, et al. Parathyroidectomy improves the quality of sleep in maintenance hemodialysis patients with severe hyperparathyroidism. J Nephrol. 2008 Mar/Apr;21(Suppl 13):S92-S6.

42. Firoz MN, Shafipour V, Jafari H, Hosseini SH, Charati JY. Sleep quality and depression and their association with other factors in hemodialysis patients. Glob J Health Sci. 2016;8(8):53485. DOI: https://doi.org/10.5539/gihs.v8n8p121

43. Lin KY, Lin YC, Wang HH. Differential effects of age on quality of sleep and depression in patients receiving maintenance haemodialysis. Psychogeriatrics. 2019;19(5):465-74. DOI: https://doi.org/10.1111/psyg.12424

45. Terzi B, Topbaş E, Ergül HÇ. Comparison of sleep quality and dialysis adequacy of patients undergoing hemodialysis. Saudi J Kidney Dis Transpl. 2019;30(6):1342-50. DOI: https://doi.org/10.4103/1319-2442.275478

46. Stein PK, Pu Y. Heart rate variability, sleep and sleep disorders. Sleep Med Rev. 2012 feb;16(1):47-66.

47. Lombardi C, Pengo MF, Parati G. Obstructive sleep apnea syndrome and autonomic dysfunction. Auton Neurosci. 2019 Nov;221:102563. DOI: https://doi.org/10.1016/j.autneu.2019.102563

48 Spiegelhalder K, Fuchs L, Ladwig J, Kyle SD, Nissen C, Voderholzer $\mathrm{U}$, et al. Heart rate and heart rate variability in subjectively reported insomnia. J Sleep Res. 2011;20(1 Pt 2):137-45. DOI: https://doi. org/10.1111/j.1365-2869.2010.00863.x

49 Casement MD, Goldstein TR, Merranko J, Gratzmiller SM, Franzen PL. Sleep and parasympathetic activity during rest and stress in healthy adolescents and adolescents with bipolar disorder. Psychosom Med. 2019 Dec;81(9):782-90. DOI: https://doi.org/10.1097/PSY.0000000000000737

50. Wang C, Deng WJ, Gong WY, Zhang J, Zhang QZ, Ye ZC, et al. Nocturnal hypertension correlates better with target organ damage in patients with chronic kidney disease than a nondipping pattern. J Clin Hypertens (Greenwich). 2015 Jun;17(10):792-801. DOI: https://doi.org/10.1111/jch.12589

51 Chan CT, Hanly P, Gabor J, Picton P, Pierratos A, Floras JS. Impact of nocturnal hemodialysis on the variability of heart rate and duration of hypoxemia during sleep. Kidney Int. 2004 Feb;65(2):661-5.

52. Sukegawa M, Noda A, Soga T, Adachi Y, Tsuruta Y, Ozaki N, et al. Comparison of sleep-disordered breathing and heart rate variability between hemodialysis and non-hemodialysis days in hemodialysis patients. Nagoya J Med Sci. 2008 Aug;70(3-4):83-8.

53. Wei CY, Chung TC, Wu SC, Chung CF, Wu WP. The subjective sleep quality and heart rate variability in hemodialysis patients. Ren Fail. 2011 Feb;33(2):109-17. DOI: https://doi.org/10.3109/0886022X.2010.541578

54 Roumelioti ME, Ranpuria R, Hall M, Hotchkiss JR, Chan CT, Unruh ML, et al. Abnormal nocturnal heart rate variability response among chronic kidney disease and dialysis patients during wakefulness and sleep. Nephrol Dial Transplant. 2010 Nov;25(11):3733-41. DOI: https://doi.org/10.1093/ndt/gfq234 